\title{
Sustainability in Metallurgy
}

\author{
ZHIWEI PENG, ${ }^{1,4}$ DEAN GREGUREK, ${ }^{2,5}$ and CHRISTINE WENZL ${ }^{3,6}$ \\ 1.-School of Minerals Processing and Bioengineering, Central South University, Changsha, \\ Hunan 410083, People's Republic of China. 2.-RHI AG, Technology Center Leoben, Magnesitstrasse \\ 2, 8700 Leoben, Austria. 3.-RHI AG, Wienerbergstrasse 9, 1100 Vienna, Austria. 4.-e-mail: \\ zwpeng@csu.edu.cn. 5.—e-mail: Dean.Gregurek@rhi-ag.com. 6.—e-mail: Christine.Wenzl@rhi-ag.com
}

Sustainable metallurgical processes encompass new theory and techniques regarding the optimization of existing processes for improved energy efficiency, enhanced environmental benefits, and increased resource/waste/by-product utilization. ${ }^{1-4}$ This special topic, "Sustainability in Metallurgy," is dedicated to presenting metallurgical processes and related research aimed at improving the sustainability of metal production. For this objective, six articles were collected in this topic, demonstrating how recent progress in metallurgy theory and practice can result in improved sustainability.

The sustainable development of metallurgical process must be built on a deep understanding of thermodynamic behavior of related substances. In the first article, which is titled, "Henry's Law Activity of Oxygen in Molten Iron," J. W. Matousek proposes a tentative model for evaluation of the thermodynamic behavior of oxygen in molten iron at concentrations below $100 \mathrm{ppm}$. The findings are deemed a necessary complement to thermodynamics of oxygen in iron as the classic equations were derived in experimental programs in which the oxygen content was above $200 \mathrm{ppm}$.

The traditional blast furnace ironmaking process suffers huge energy consumption, serious environment pollution, and high $\mathrm{CO}_{2}$ emission. Unlike the traditional blast furnace, the oxygen blast furnace exhibits the potential to significantly reduce energy consumption and $\mathrm{CO}_{2}$ emissions. In the second and third articles titled, "Numerical Study of the Gas Distribution in an Oxygen Blast Furnace. Part 1: Model Building and Basic Characteristics," and "Numerical Study of the Gas Distribution in an Oxygen Blast Furnace. Part 2: Effects of the Design and Operating Parameters," Zongliang Zhang et al. report the influence of recycling gas distribution from shaft tuyere on heat distribution and energy

Zhiwei Peng and Dean Gregurek are the guest editors for the Pyrometallurgy Committee of the TMS Extraction \& Processing Division, and coordinators of the topic Sustainability in Metallurgy in this issue. utilization in oxygen blast furnace by developing a multifluid model. With this model, optimum design and operating parameters of the furnace were achieved, contributing to improved sustainability of the ironmaking process.

Biomass char is a renewable resource that can be produced from practically any carbonaceous material, including agricultural and forestry waste. In the fourth article titled, "Production of LowPhosphorus Molten Iron from High-Phosphorus Oolitic Hematite Using Biomass Char," Huiqing Tang et al. demonstrate the potential of biomass char as a suitable reducing agent for reduction of the hematite to obtain metallic product with low carbon content. The phosphorus content of the product was further reduced in the smelting stage by addition of sodium carbonate. With this approach, hot metal with iron recovery rate of $78 \%$ to $75 \%$ and phosphorus content of $<0.3$ wt.\% was obtained.

For production of nickel pig iron, nickel-bearing resources like nickeliferous laterite ores are often processed using complex energy intensive production routes. To improve the process economics a simple route, namely the blast furnace smelting process, was developed. This process involves a stage of sintering of the mixture of the ore, coke breeze and flux, prior to smelting. In the fifth article titled, "Evaluation of Sintering Behaviors of Saprolitic Nickeliferous Laterite Based on Quaternary Basicity," Jun Luo et al. show the effect of quaternary basicity on sintering behavior of saprolitic laterite in the reducing atmosphere by controlling the addition of calcium oxide. The sintering indexes, including vertical sintering velocity, yield, and productivity, were improved by optimizing the quaternary basicity.

The extraction of gold from complex ores usually involves the use of toxic agents such as cyanides. This will inevitably lead to cyanide contamination of the final process water, which requires further treatment before discharge. The last article in this series by M. Ordiales et al., "Potassium 
Permanganate as an Alternative for Gold Mining Wastewater Treatment," demonstrates the feasibility of using potassium permanganate as a reagent for cyanide oxidation in wastewater. Potassium permanganate was confirmed as an effective and reliable oxidizing agent to remove cyanide from gold mining wastewater due to its efficiency, safety, and high yield.

The selected articles in this topic exemplify how recent efforts trigger the development of metallurgy by improving its sustainability, from basic theories through methodologies to practices. We hope the readers will find this collection of the articles interesting, informative, and best of all, practical.

The following papers being published under the topic of sustainability in metallurgy provide excellent details and research on the subject. To download any of the papers, follow the URL: http://link. springer.com/journal/11837/67/9/page/1 to the table of contents page for the September 2015 issue (vol. 67, no. 9).

- "Henry's Law Activity of Oxygen in Molten Iron," by J. W. Matousek.

- "Numerical Study of the Gas Distribution in an Oxygen Blast Furnace. Part 1: Model Building and Basic Characteristics," by Zongliang Zhang, Jiale Meng, Lei Guo, and Zhancheng Guo.

- "Numerical Study of the Gas Distribution in an Oxygen Blast Furnace. Part 2: Effects of the Design and Operating Parameters," by Zongliang Zhang, Jiale Meng, Lei Guo, and Zhancheng Guo.

- "Production of Low-Phosphorus Molten Iron from High-Phosphorus Oolitic Hematite Using Biomass Char," by Huiqing Tang, Tengfei Qi, and Yanqi Qin.

- "Evaluation of Sintering Behaviors of Saprolitic Nickeliferous Laterite Based on Quaternary Basicity,” by Jun Luo, Guanghui Li, Mingjun Rao, Yuanbo Zhang, Zhiwei Peng, Qian Zhi, and Tao Jiang.

- "Potassium Permanganate as an Alternative for Gold Mining Wastewater Treatment," by M. Ordiales, D. Fernández, L. F. Verdeja, and J. Sancho.

\section{REFERENCES}

1. R.J. Fruehan, Metall. Mater. Trans. B 40, 123 (2009).

2. S. Wang, JOM 61, 26 (2009).

3. M.A. Reuter, Waste Biomass Valori. 2, 183 (2011).

4. Z. Peng and J.Y. Hwang, Int. Mater. Rev. 60, 30 (2015). 